\title{
A SURVEY OF FEMALE GENITAL SCHISTOSOMIASIS OF THE LOWER REPRODUCTIVE TRACT IN THE VOLTA BASIN OF GHANA
}

\author{
D. YIRENYA-TAWIAH ${ }^{1}$, C. AMOAH ${ }^{2}$, K. A. APEA-KUBI ${ }^{3}$, M. DADE $^{4}$, M. ACKUMEY ${ }^{5}$, \\ T. ANNANG ${ }^{6}$, D. Y. MENSAH ${ }^{7}$ and K. M. BOSOMPEM ${ }^{8}$
}

${ }^{1}$ Volta Basin Research Project, University of Ghana, P.O. Box 209, Legon, Ghana ${ }^{2}$ Department of Animal Biology and Conservation Science, University of Ghana, Legon, Ghana ${ }^{3}$ Department of Obstetrics \& Gynaecology, Korle-Bu Teaching Hospital, Accra-Ghana ${ }^{4}$ Department of Environment, Volta River Authority, Akosombo, Ghana ${ }^{5}$ School of Public Health, University of Ghana, Legon, Ghana ${ }^{6}$ Department of Botany, University of Ghana, Legon, Ghana ${ }^{7}$ Department of Epidemiology, Noguchi Memorial Institute of Medical Research University of Ghana, Legon, Ghana and ${ }^{8}$ Department of Parasitology, Noguchi Memorial Institute of Medical Research, University of Ghana, Legon, Ghana

Corresponding Author: Dr. D. Yirenya-Tawiah

E-mail: dzidzoy@ug.edu.gh

Conflict of Interest: None declared

\section{SUMMARY}

Objective: To determine the prevalence of female genital schistosomiasis in riparian communities in the Volta basin of Ghana,

Design: The study was a cross-sectional study conducted among women 15-49 years in the Volta Basin. Urinary schistosomiasis prevalence was determined using microscopy. A structured questionnaire was also administered to collect information on the demography, obstetric history and reproductive health experiences. Cervical punch biopsy was collected from women who consented to be screened for FGS. Descriptive statistics was used to determine frequency of occurrence, chi squared and logistic regression to identify associated variables

Results: Urinary schistosomiasis prevalence among the women was $24.8 \%$ while $10.6 \%$ of them diagnosed with FGS. More FGS diagnosed women $(57.7 \%$, p value $=0.04 \%$ ) were observed to report copious discharge, vaginal itch $(80.8 \%, \mathrm{p}=0.042)$ and lower abdominal pain $(66.7 \%, \mathrm{p}=0.041)$ compared to FGS negative women. The predominant abnormal observation of the lower genital tract made was erythematous cervix (18.8\%).

Conclusion: The study confirms the reproductive health symptoms associated with FGS and recommends awareness creation on FGS among women in endemic communities to facilitate early treatment.

Key words: Female Genital Schistosomiasis, lower abdominal pain, vaginal itch, Volta Basin

\section{INTRODUCTION}

Female Genital Schistosomiasis (FGS) occurs when ova or adults of the trematode parasite, Schistosoma $s p$ ectopically locate in the female genital system. ${ }^{1}$ Although any of the Schistosoma parasites that affect humans may cause FGS, its occurrence is more common with $S$. haematobium infections, the causative agent of urinary Schistosomiasis. ${ }^{2-3}$

FGS prevalence in urinary schistosomiasis endemic areas is estimated to range between $30-50 \%{ }^{1}$ Even in the absence of ova excretion in women, $23-41 \%$ of them are found to have genital schistosomiasis. ${ }^{4-5}$ FGS has been implicated in women's reproductive health.

The consequences include spontaneous abortions, infertility, postcoital bleeding, dypareunia vaginal discharge, pelvic pain, and genital itch., ${ }^{4,67}$ It has also been shown to facilitate the transmission of sexually transmitted infections such as the human papilloma virus (HPV) and HIV-1through the stimulation of the immune system with a strong bias towards type 2 CD4 helper $\mathrm{T}$ cells (Th2).

HIV replication is known to proceeds rapidly in activated T cells thus FGS is considered a risk factor to HIV transmission ${ }^{1}$. Urinary schistosomiasis is prevalent and widespread in Ghana. However, there is paucity of information of FGS in the country and even worldwide.

Although as high as 40 million women of child bearing age are infected with schistosomiasis and 20 million suffer from the disease, the actual contributions of schistosomiasis to maternal health and birth outcomes for instance are not known. ${ }^{8}$ 
Also, schistosomiasis control efforts are mostly targeted at children whilst neglecting other risk groups such as reproductive aged women. To influence schistosomiasis control policy, through evidence based studies, to direct efforts to women in reproductive age in Ghana, this study was conducted to provide baseline data on FGS of the lower reproductive tract in the Volta basin of Ghana and determine how the disease is manifested in infected women.

\section{METHODS}

\section{Study Area}

The study was conducted in fifteen riparian communities on the Afram arm of the Volta River and the Lower Volta basin of Ghana. The women of these communities generally engaged in trading including fish mongering and subsistence farming. Their main water contact activity was collection of water from the Volta Lake for domestic use. Most of the women were also exposed to water contact through water transport as they moved from one community to another.

\section{Study Design}

This was a cross-sectional study carried out among women 20-49 years who are permanent residents in riparian communities on the Afram arm of the Volta River and the lower Volta Basin. Women 15-19 years, although considered to be within the reproductive age, were excluded on the grounds of being among the school age group.

However those within this age group who were married and wanted to participate were recruited. Virgins, pregnant women, menstruating women, postnatal women and women who had undergone hysterectomy were excluded from the screening process. Initial visits were made to the villages to explain the details of the study to both community leaders and community members to ensure approval and support to participate in the study.

Meetings were also held with the women in the villages to solicit their opinions and suggestions and address their concerns. Community members were informed of the use of identification numbers instead of names and confidentiality of study findings. Eligibility to participate in the study was determined by gender, informed consent and permanent residency in village. Women who consented to participate were examined by a gynaecologist for their fitness to participate in the study.

Those who were deemed fit by the doctor were administered a structured questionnaire entailing socio- demographic information and reproductive health experiences.

Mid-day urine samples were collected and examined for S. haematobium ova by microscopy. After this cervical biopsy collection was done by the gynaecologist who inspected the vulva and vagina for abnormalities.

With the aid of a sterile disposable vaginal speculum, the appearance of the cervix was also noted, and cervical biopsy was taken from suspicious lesions in the anterior lip of the cervix using a $5 \mathrm{~mm}$ cervical punch biopsy forceps. The collected tissue was immediately placed on a microscope glass slide. A drop of trypan blue was added to the tissue to facilitate clearing and identification of ova.

The tissue sample was then compressed between two microscope glass slides secured with a tape and placed in a moist chamber at $4^{\circ} \mathrm{C}$ for transportation to the Noguchi Memorial Institute for Medical Research (NMIMR) laboratory for analysis. To minimize non participation bias, free transport to the screening centres and lunch were provided to participants.

Where district hospitals were over $100 \mathrm{~km}$ away from the community and local health facilities were found to be unsuitable (such as bat infested premises) for use, make shift screening centres were set up for the gynaecological screening.

All women diagnosed for FGS were treated with praziquantel within a period of 3 months, and those found with other health conditions during screening were referred through the existing health systems to the nearest appropriate health facility for treatment.

Treatment for urinary schistosomiasis was offered to all infected subjects including those who did not consent to gynaecological screening. Ethical clearance was given by the Institutional Review Board of Noguchi Memorial Institute for Medical Research.

\section{Statistical analysis}

The data was entered and analysed using SPSS statistical software, version 16.0. Descriptive statistics were obtained through frequencies and cross tabulations. Comparison between groups was made using Chi- square test and fisher exact tests where appropriate. The analysis was two-tailed and the level of significance set at 5\%. Binary logistic regression was also used to assess the effects of confounders where necessary. 


\section{RESULTS}

Four hundred and twenty (420) subjects consented to undergo gynaecological screening. About ninety three $(93.4 \%)$ of them were married and $(6.6 \%)$ in a permanent sexual relationship.

The mean age of the study participants was 33.6 years and the modal age 40 years. Out of the 420 women, 25 were excluded from undergoing screening: 6 menstruating on the day of screening, 2 hysterectomy done, 3 with early pregnancy, 6 not feeling well, 4 husbands refused their wives participation and 4 withdrew consent. Three hundred and ninety five of them were therefore screened gynaecologically and within this cohort 371 of them provided urine.

\section{Schistosomiasis Prevalence}

Urine schistosomiasis prevalence determined among the women was $25.3 \%$ (Table 1), while FGS prevalence found was $10.6 \%$ (42/395). Only 13 (14.1\%) of urinary schistosomiasis positive women were diagnosed with FGS and $24(8.6 \%)$ of the urinary schistosomiasis negative women diagnosed for FGS.

No significant association was observed between the occurrence of urinary schistosomiasis and FGS of the cervix $\left(\chi^{2}=1.79, \mathrm{p}\right.$ value $\left.=0.18\right)$. While urinary schistosomiasis prevalence decreased with increasing age FGS prevalence remained relatively stable among the various age groups (Figure 1).

Table 1 Female genital schistosomiasis prevalence among subjects screened for urinary schistosomiasis

\begin{tabular}{|l|l|l|l|}
\hline & \multicolumn{3}{|l|}{$\begin{array}{l}\text { FGS occurrence among study sub- } \\
\text { jects }\end{array}$} \\
\hline $\begin{array}{l}\text { Urinary schis- } \\
\text { tosomiasis } \\
\text { status }\end{array}$ & $\begin{array}{l}\text { FGS Posi- } \\
\text { tive (\%) }\end{array}$ & $\begin{array}{c}\text { FGS Nega- } \\
\text { tive (\%) }\end{array}$ & Total (\%) \\
\hline Positive & $13(14.1)$ & $79(85.9)$ & $92(24.8)$ \\
\hline Negative & $24(8.6)$ & $255(91.4)$ & $279(75.2)$ \\
\hline Total & $37(10.0)$ & $334(90.0)$ & $371(100)$ \\
\hline
\end{tabular}

\section{Manifestation of Female Genital Schistosomiasis}

Vaginal itching $(62.3 \%)$ and vaginal discharge $(56 \%)$ were the most frequently reported reproductive health problem. Although no significant difference was observed between women with FGS reporting vaginal discharge and women without FGS (p value $=0.55$ ), more FGS diagnosed women $(57.7 \%)$ were observed to report copious discharge than women without FGS $(36.9 \%)(\mathrm{p}$ value $=0.04)$. Women with FGS also reported more vaginal itch $(80.8 \%, \mathrm{p}=0.042)$ and lower abdominal pain $(66.7 \%, \mathrm{p}=0.041)$ than FGS negative women.

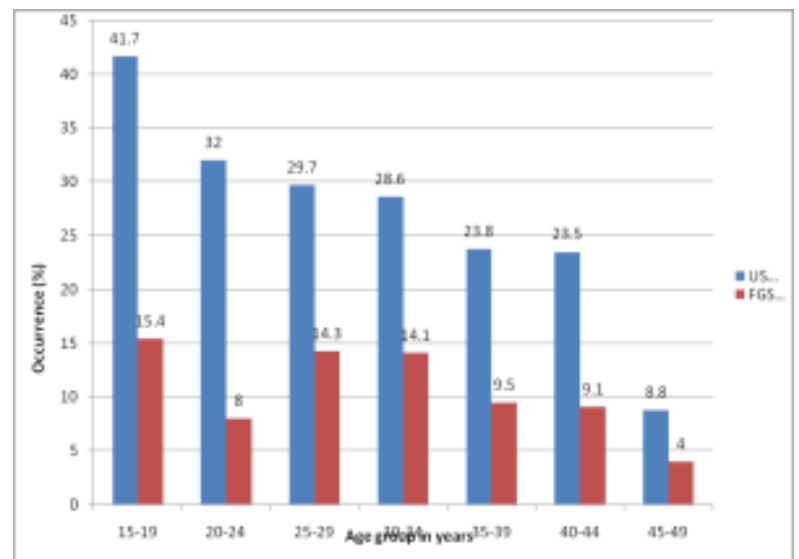

Figure 1 Age distribution of urinary schistosomiasis and female genital schistosomiasis in the study population

While number of births a woman has had confounded the effect of FGS on lower abdominal pain $(\mathrm{OR}=1.8)$, irregular menstruation $(\mathrm{OR}=4.6)$, odorous vaginal discharge $(\mathrm{OR}=4.9)$ and dyspareunia $(\mathrm{OR}=2.2)$ enhanced lower abdominal pain in the presence of FGS. Post-coital bleeding was, however, not associated with FGS ( $p>0.05)$ (Table 2).

Table 2 Logistic regression to determine confounders of FGS on Lower Abdominal pain

\begin{tabular}{|l|c|c|c|c|}
\hline \multicolumn{1}{|c|}{ Variables } & $\begin{array}{c}\text { Crude OR } \\
(\mathbf{9 5 \%} \text { CI }\end{array}$ & $\begin{array}{c}\text { p- } \\
\text { value }\end{array}$ & $\begin{array}{c}\text { Adjusted OR } \\
(\mathbf{9 5 \%} \text { CI) }\end{array}$ & $\begin{array}{c}\text { p- } \\
\text { value }\end{array}$ \\
\hline FGS & $2(1.01-3.92)$ & 0.044 & & \\
\hline $\begin{array}{l}\text { Number of } \\
\text { births }\end{array}$ & & & $1.8(0.93-3.63)$ & 0.08 \\
\hline Irregular menstruation & & $2(1.02-3.95)$ & 0.043 \\
\hline $\begin{array}{l}\text { Odorous dis- } \\
\text { charge }\end{array}$ & & & $4.9(1.5-15.01)$ & 0.005 \\
\hline Dyspareunia & & & $2.2(1.12-4.48)$ & 0.022 \\
\hline $\begin{array}{l}\text { Post coital } \\
\text { bleeding }\end{array}$ & & & $1.8(0.94-3.68)$ & 0.07 \\
\hline
\end{tabular}

Table 3 Clinical observation of external genitalia

\begin{tabular}{|l|l|l|}
\hline Clinical Observation & No. Positive & \% Positive \\
\hline Vulva/Vagina & $3 / 398$ & 0.8 \\
\hline Ulcer & $3 / 398$ & 0.8 \\
\hline Oedema & $8 / 398$ & 2 \\
\hline Erosion & $133 / 398$ & 33.4 \\
\hline Discharge & $73 / 389$ & 18.8 \\
\hline Cervix & $6 / 387$ & 1.6 \\
\hline Erythematous & $12 / 388$ & 3.1 \\
\hline Punctuate & $12 / 388$ & 3.1 \\
\hline Sandy patches &
\end{tabular}


FGS associated abnormalities of the lower reproductive tract

The abnormalities of the lower reproductive tract observed in the women have been shown in Table 3 .

\section{DISCUSSION}

Ghana is one of the first five countries implementing the integrated control program for Neglected Tropical Diseases (NTD). However due to lack of evidence based data to highlight the reproductive health importance of schistosomiasis, the strategy to reduce disease burden continues to mainly focus on children ${ }^{9}$ while neglecting other risk groups including reproductive aged women.

This study provides evidence based data on female genital schistosomiasis in the Volta Basin. The study found $10.6 \%$ of women in their reproductive age to be positive for FGS. Although other studies reported higher prevalence, $49 \%$ in Zimbabwe ${ }^{4}, 36 \%$ in Northern Tanzania ${ }^{10}$ and $33.3 \%$ in Madagascar ${ }^{7}$, the prevalence found in the Volta Basin is still significant to be of public health concern.

Considering that health consequences of FGS include infertility, miscarriages and ectopic pregnancies, and the negative impact of these on families and societies are well known, this study brings out the need to further investigate FGS impact on women's health. For instance, half of women studied in a hamlet in Egypt were found to have FGS and its associated reproductive health morbidity ${ }^{11}$. However, these women were unwilling to complain about their health situation to their husbands for fear of being divorced or husband taking another wife.

Also, because FGS symptoms are generally not distinguishable from those of sexually transmitted infections (STI) the condition is most often mistaken as an STI, which is mostly stigmatized. A possible reason that may be ascribed to the observed prevalence of FGS in this study may be related to low virulence of the parasite type in this region. ${ }^{12}$

As early as 1956, it was shown that, the West African strain of $S$. haematobium produced a milder form of schistosomiasis morbidity and mortality compared to the Egyptian strain of the parasite ${ }^{12}$. , Differences in urinary tract pathology associated with Schistosoma infection were reported among various regions of Africa and even within communities. ${ }^{13,14}$

Other factors such as hosts immunity and environmental influences also have significant effects on schistosomiasis morbidity. Urinary schistosomiasis prevalence followed the standard trend of decreasing with increasing age which was consistent with findings from earlier studies. ${ }^{15}$

Also as observed by this study, the stable trend of FGS infection among the various age groups indicates that all women in the reproductive age are at the risk of FGS. Some studies have determined the occurrence of sandy patches as pathognomonic for FGS. ${ }^{16,17}$ However, in this study, gynaecological examination did not include colposcopy, which promotes better observation of sandy patches on the cervix..$^{11,16}$

This explains in part the low observation of sandy patches in this study and the insignificant association observed $(\mathrm{p}=0.63)$ between it and FGS diagnosed by crushed biopsy.The predominant pathologic cervical abnormality observed among the women was erythematous cervix. Other observations were strawberry cervical growths, punctuate cervix and sandy patches.

Generally, women with FGS were seen more with genital lesions than women without schistosomiais $(\mathrm{p}>0.05)$. The presence of cervical lesions in association with schistosomiasis has been well reported to be indicative of various health problems including cervical cancer. $^{1,5,6}$

Vulva lesions in both women and girls have also been documented in case reports of FGS ${ }^{18,19}$ This occurs when worms migrate from the ano-rectal plexus to the internal pudendal vein (lower part of the sacral plexus) and the posterior labial vein or via the vesical plexus to the santorini plexus via the deep vein of the clitoris. ${ }^{18}$

Feldmeier and his colleagues ${ }^{2}$ therefore suggested that, any woman with urinary schistosomiasis may at least or temporarily have Schistosoma lesions in her genitals. This may account for urinary schistosomiasis positive women showing more vulva lesions than uninfected women $(\mathrm{p}>0.05)$. Significant symptoms associated with FGS found in this study were copious vaginal discharge, vaginal itch and lower abdominal pain.

This is comparable to the study conducted by Kjetland et al., (2008) who found genital itch, malodorous and abnormally coloured discharge as significant symptoms associated with FGS infection in rural Zimbabwean women $^{20}$. Leutcher et al. ${ }^{7}$ found pelvic pain, vaginal discharge and irregular menstruation as predictors of FGS. It was however not surprising that number births a woman had confounded the effects of lower abdominal pain. Spontaneous vaginal deliveries (SVD) are known to have a toll on a woman's pelvic region. 
Thus in rural communities were successful deliveries are mainly SVDs, the more births a woman went through the more she may be of risk of pelvic related problems.

Contrary to findings from this study, Kjetland et al. ${ }^{20}$ reported no gynaecological complaints associated with urinary schistosomiasis infection whereas women with genital schistosomiasis significantly reported more stress incontinence and frequent micturition.

Individuals diagnosed with urinary schistosomiasis in this study reported more dyspareunia (painful sexual intercourse $\quad(p$-value $=0.03)$. Admitting that dyspareunia may be common younger women initiating sex and postmenopausal women as a result of decreased oestrogen, other and individuals with sexually transmitted infections, these variables did not confound dyspareunia in urinary schistosomiasis infected women in this study.

Although selection bias may affect the epidemiological validation of these results, these findings nevertheless confirm the importance of schistosomiasis in reproductive health. As the consequences of this condition may be impacting negatively on maternal health, it will be recommended that awareness is created about female genital schistosomiasis in endemic areas.

\section{ACKNOWLEDGEMENT}

Sincere thanks go to the Ghana AIDS Commission and the Ministry of Water Resources, Works and Housing for funding the study. Also acknowledged are departments of Parasitology and Bacteriology of Noguchi Memorial Institute for Medical Research (NMIMR) for technical support, Public health Unit of the Volta River Authority for technical support and supply of Praziquantel for treatment, The District Health Managements teams of districts involved in study, Community leaders and community members without whose participation the study would have been impossible.

\section{REFERENCES}

1. Poggensee, G. , Feldmeir, H. and Krantz, I. Schistosomiasis of the Female Genital Tract: Public Health Aspects. Parasitology Today, (1999). 5(9), 378-381

2. Feldmeier, H., Daccal, R.C., Martins, M.J., Soares, V and Martins, R. Genital Manifestations of Schistosoma mansoni in Women: Important but Neglected. Mem. Inst. Oswaldo Cruz, (1998). 93(1), 127-133.
3. Felmeier, H., Poggensee, G., Krantz, I., and Helling-Giese, G. Female genital schistosomiasis. New challenges from a gender perspective. Trop. Geograph Med, (1995b). 47, 1-15

4. Kjetland, E.F., Ndhlovu, P.D., Mduluza, Gomo, E., Gwanzura, L., Mason, P.R., Kurewa, E.N., Midzi, N., Friis, H. And Gundersen, S.. Simple clinical manifestations of genital schistosoma haematobium in Rural Zimbawean women. Am.J. Trop.Med.Hyg, G (2005). 72(3), 311-319

5. Poggensee, G., Kiwelu, I., Saria, M., Richter L., Krantz, I. and Feldmeir, H. Schistosomiasis of the lower reproductive tract without egg excretion in urine. American American Journal of Tropical Medicine and Hygiene, (1998). 59(5), 782-783

6. Poggensee, G. Sahebali, S., Marck, V.E., Swai, B., Krantz, I. and Felmeir, H. Diagnosis of Genital cervical schistosomiais: Comparison of Cytological, Histopathological and Parasitological examination. American Journal of Tropical Medicine and Hygiene, (2001). 65(3), 233-236

7. Leutscher, P., Ravaolimalala, C., Raharisolo, C.E., Ramarokoto, M., Rasendramino, A., Raobelison, B., Vennervald P. E and Feldmeir, H. Clinical findings in female genital schistosomiasis in Madagascar. Tropical Medicine and International Health, (1998) 3(4), 327-33

8. Engels, D, Chitsulo, L., Montresor, A and Savioli, L. The global epidemiological situation of schistosomiasis and new approaches to control and research. Acta Trop. (2002). 82, 139-146

9. Ghana Health Service. Two year strategic plan for Integrated Neglected Tropical Diseases Control in Ghana, 2007-2008. Ghana Health Service. (2007)

10. Poggensee, G., Krantz, I., Kiwelu, I. and Feldmeir, H.. Screening of Tanzania women of childbearing age for urinary schistosomiasis: validity of urine reagent strip readings and selfreported symptoms. Bulletin of World Health Organization, (2000). 78(4), 542-548

11. Talaat, M., Watts, S., Mekheimar, S., Ali, H.F. and Howaida, $H$. The social context of reproductive health in an Egyptian hamlet: a pilot to identify female genital schistosomiasis. Social Science and Medicine, (2004). 58, 515-524

12. McCullough, F. The susceptibility and resistance of Bulinus (Physopsis) globosus and Bulinus (Bulinus) truncatus rohlfsi to two strains of Schistosoma haematobium in Ghana. Bull World Health Organisation 1959, 20(1) 75-85

13. Elem B and Vandal M.T. Bilharziasis of the urinary tract in Zambia (observation on 100 consecative cases). Med J Zambia 1981, 15(14) $48-51$ 
14. Pugh R.N, Burrows J.W, Tayo M.A. Malumfasi endemic diseases research project XIV, Increasing Schistosomiasis transmission 1980. Annal .Trop med and Para 74(5) 569-70

15. Fulford, A.J.C., Webster, M., Ouma, J.H., Kimani, G., and Dunne, D.W. Puberty and age related changes in susceptibility to schistosome infection. Parasitology Today, (1998) 14, 23-26

16. Helling-Giese, G., Sjaatad, A., Poggense, G., Kjetland, E.F., Richter, J., Chitsulo, L., Kumwenda, N., Racz, P., Roald, B., Gundersen, S.G., Krantz, I and Feldmeier, H. Female genital schistosomiasis (FGS): relationship between gynaecological and histopathological findings. Acta Trop, (1996). 62, 257-267.

17. Kjetland, E.F, Helling-Giese, G XXX. Female genital schistosomiasis due to $\mathrm{S}$. Haematobium.
Clinical and parasitological findings in women in rural Malawi. Acta Tropica, (1996). 62, 239-255

18. Laven, J.S.E., Vleugels, M.P.H., Dofferhoff, A.S.M and Bloembergen, P. Schistosomiasis haematobium as a cause of vulvar hypertrophy. European Journal of Obstetrics and Gynaecology and Reproductive Biology, (1998). 79(2), 213-216

19. Goldsmith P.C.,Leshe T.A., Saws v, Bryceson A.D, Allason-Jones E, Dowd P.W, Lesions of Schistosomiasis mime kinp warts on the vula. BMJ. 1993, 307(6903) 556-557

20. Kjetland, E.F., Ndhlovu, P.D., Kurewa, E.N., Midzi, N., Gomo, E., Mduluza, T., Friis, H. And Gundersen, S.G. Prevention of Gynaecologic Contact Bleeding and Genital Sandy Patches by Childhood Anti-Schistosomal Treatment. Am. J. Trop Med. Hyg, (2008) 79(1), 79-83 